\title{
Association between early diastolic dysfunction and increased peri-/epicardial fat: A CMR based study
}

Darius Dabir*, Rami Homsi, Daniel Kuetting, Julian A Luetkens, Christian Marx, Martin Sprinkart, Juergen Gieseke, Hans H Schild, Daniel K Thomas

From 19th Annual SCMR Scientific Sessions

Los Angeles, CA, USA. 27-30 January 2016

\section{Background}

Previous studies have shown that increased peri- and epicardial fat volume (PFV, EFV) leads to pathological diastolic strain (DS) and thus to cardiovascular morbidity. The aim of this study was to investigate the association between diastolic strain and EFV/PFV in obese and non-obese individuals without previous history of cardiovascular disease or additional cardiovascular risk factors.

\section{Methods}

19 healthy subjects ( 14 men, mean age 44.18 y \pm 17.95 ) underwent a comprehensive cardiac magnetic resonance (CMR) examination (1.5 Tesla, Philips Ingenia). Patients were divided into two groups: (A) obese subjects with a body mass index (BMI) $>25 \mathrm{~kg} / \mathrm{m}^{2}$; (B) non-obese subjects with a BMI $<25 \mathrm{~kg} / \mathrm{m}^{2}$. EFV and PFV were assessed using a 3D transversal ECG- and respiratory navigator gated mDixon-sequence (figure 1). FT derived systolic and diastolic circumferential strain parameters were calculated from SSFP-cine images in midventricular short axis, which were acquired prior to contrast agent injection (๑TomTec, Image Arena).

\section{Results}

Mean BMI in group A was $30.66 \mathrm{~kg} / \mathrm{m}^{2} \pm 5.71$ and in group B $22.17 \mathrm{~kg} / \mathrm{m}^{2} \pm 1.76(\mathrm{p}<0.05)$. Mean PFV and EFV were $238.61 \mathrm{ml} \pm 121.14$ and $103.47 \mathrm{ml} \pm 37.05 \mathrm{in}$ group A whereas mean PFV and EFV in group B accounted for $116.80 \mathrm{ml} \pm 43.14$ and $60.71 \pm 23.21$ respectively $(\mathrm{p}<0.05)$. Both groups revealed a peak circumferential systolic strain within a physiological range (group A:-23.60\% \pm 4.77 ; group B: $-24.95 \% \pm 3.52$; $\mathrm{p}>$ $0.05)$. Group A $(63.03 \pm 11.83)$ showed significantly

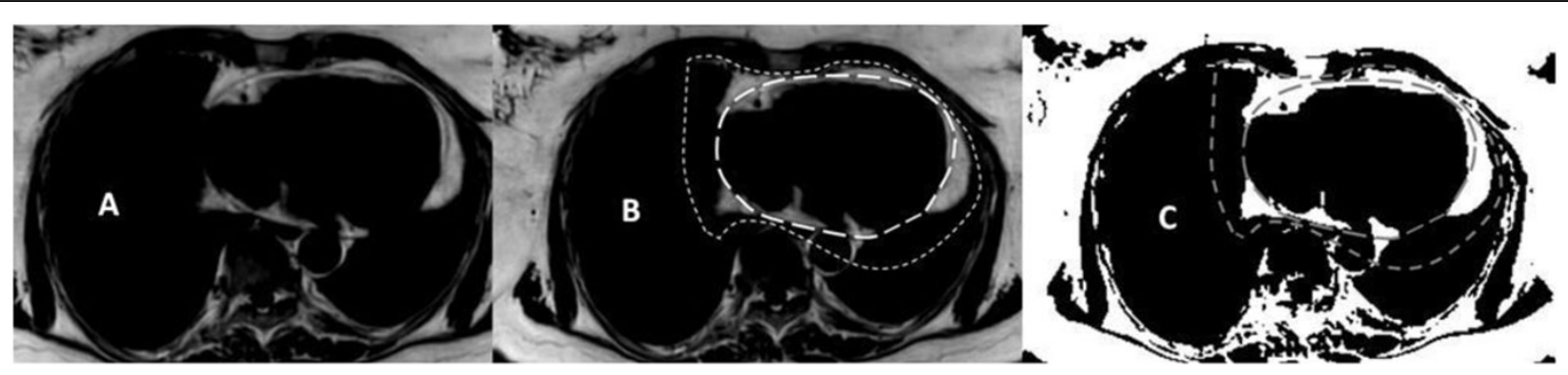

Figure 1 Dixon image analysis for measurement of pericardial and epicardial fat volume (PFV, EFV) in a 60 year old health female. A. Reconstructed fat only image. B. Reconstructed fat only image with corresponding regions of interest for EFV and PFV. C. Segemented fat voxels with transferred regions of interest.

Department of Radiology, University of Bonn, Bonn, Germany 
reduced mean early diastolic strain rates (EDSR) in comparison to group B $(82.77 \pm 16.33 ; \mathrm{p}<0.05)$. There were no significant differences between sex or age.

\section{Conclusions}

Obese subjects with increased peri-/epicardial fat volume had a significantly reduced EDSR in comparison to the non-obese control group.

Published: 27 January 2016

doi:10.1186/1532-429X-18-S1-P111

Cite this article as: Dabir et al: Association between early diastolic dysfunction and increased peri-/epicardial fat: A CMR based study. Journal of Cardiovascular Magnetic Resonance 2016 18(Suppl 1):P111.

Submit your next manuscript to BioMed Central and take full advantage of:

- Convenient online submission

- Thorough peer review

- No space constraints or color figure charges

- Immediate publication on acceptance

- Inclusion in PubMed, CAS, Scopus and Google Scholar

- Research which is freely available for redistribution

Submit your manuscript at www.biomedcentral.com/submit
C BioMed Central 